\title{
A Study on Durability Properties of Scc And Conventional Concrete with Recycled Coarse Aggregate
}

\author{
Midhu Jolly ${ }^{1}$, Prof. Praveen Mathew ${ }^{2}$ \\ ${ }^{1}$ (Civil Engineering, M.A College of Engineering/M G University, India) \\ ${ }_{2}^{2}$ (Civil Engineering , M.A College of Engineering/M G University, India)
}

\begin{abstract}
As the concept of SCC and conventional concrete is different, traditional models cannot be extrapolated without any verification in SCC, however the matrix shows a very high filler content, much higher than in traditional concrete. Although self-compacting concrete (SCC) is currently used in many countries, there is a fundamental lack of the intrinsic durability of the material itself. It is widely reported that selfcompacting concrete mixtures usually show improved durability characteristics as compared with normally vibrated concretes. In the current era, the present day world has witnessed a phenomenal rise in construction activities over decades. The demolition of existing old structures inevitably results into the generation of construction and demolition $(C \& D)$ waste, the disposal of which is a problem causing environmental hazards. The main target of this research is the evaluation of the durability properties and pore structure studies of medium strength self-compacting concretes with recycled aggregates and their comparison with those measured on reference normally vibrated concretes.
\end{abstract}

Keywords: Self Compacting Concrete, Durability, Conventional Concrete, Recycled Coarse Aggregate, Deterioration

\section{Introduction}

Concrete is a composite material composed of aggregate bonded together with a fluid cement which hardens over time. Most use of the term "concrete" refers to Portland cement concrete.Science and technology advances at a rapid rate and has revolutionalised every fields of day to day life. Construction industry also has equipped with many new technologies that replaces the outdated traditional methods. One of such innovation led to the formation of self compacting concrete (SCC) which does not require any manual or mechanical vibrators for its compaction. It flows under its own weight filling all the voids and spaces and achieving full compaction even in the presence of highly congested reinforcements [4]. It was developed by Okamura and associates in Japan during 1988 and considered as a highly workable concrete that can flow through densely reinforced and complex structural elements and adequately fill all voids without segregation, excessive bleeding and the need for vibration or other mechanical consolidation. The unique characteristics of SCC are a rapid rate of concrete placement with very less time. SCC offers a very high level of homogeneity; minimize the concrete void spaces and have uniform concrete strength and also provides the superior level of finishing and durability of structure. SCC also achieves same engineering properties and durability as traditional vibrated concrete. In recent years, the use of SCC has gained a wider acceptance. Rapid industrial development causes serious problem all over the world such as depletion of natural aggregates and creates enormous amount of waste material from construction and demolition activities [2]. One of the ways to reduce this problem is to utilize recycled concrete aggregate in the production of concrete. The use of recycled products can reduce the demands for new raw materials. Recycled aggregate is one of the major construction wastes capable of being recycled and reuse.

\subsection{Difference between Scc And Traditional Concrete}

As the concept of SCC and traditional concrete is different, traditional models cannot be extrapolated without any verification.in SCC however the matrix shows a very high filler content, much higher than in traditional concrete. A good understanding of durability of SCC could be obtained by investigating the micro structure of SCC, in comparison with the traditional concrete.The microtomographical reconstruction of air void system of traditional concrete and self-compacting concrete indicates that the pore system of SCC is different than traditional concrete.

\subsection{Significance of Durability Studies}

When designing a concrete mix or concrete structure, the exposure condition at which the concrete is supposed to withstand is to be assessed. The environmental pollutions are increasing day by day particularly in urban areas and industrial atmospheres. It is reported that in industrially developed countries over $40 \%$ of total resources of the building industries are spend on repairs and maintenance. So considerations for durability of modern concrete constructions assume much more importance. 


\subsection{Recycled Coarse Aggregate}

India has established itself as one of the world's fastest growing economies and this growth has brought with it a significant boost in construction activities. Currently construction sector in India is growing at the rate of $10 \%$ per annum. With the increasing demand for build spaces and scarcity of land, a trend of redevelopment projects is upcoming which is contributing to more and more construction and demolition waste. Presently construction and demolition waste $(C \& D)$ generation in India accounts up to 23.75 million tons annually and these figures are likely to double fold up to 2016. The management of C\&D waste is a major concern for town planners due to the increasing amount of construction waste, continuing shortage of dumping sites, increase in transportation and disposal cost and above all growing concern about pollution and environmental deterioration. Among various $\mathrm{C} \& \mathrm{D}$ wastes, reuse of recycled concrete aggregate has opened a whole new range of possibilities for reusing materials in construction due to its great environment effect.[17]

\subsubsection{Slump-Flow And T500 Time For Scc}

\section{Test Results And Discussions}

The slump-flow and T500 time is a test to assess the flowability and the flow rate of self-compacting concrete in the absence of obstructions. The result is an indication of the filling ability of self-compacting concrete. Slump flow test is a sensitive test that will normally be specified for all SCC, as the primary check that the fresh concrete consistence meets the specification. The T500 time is also a measure of the speed of flow and hence the viscosity of the SCC.

The fresh concrete is poured into a cone as used for slump cone test. When the cone is withdrawn upwards the time from commencing upward movement of the cone to when the concrete has flowed to a diameter of $500 \mathrm{~mm}$ is measured; this is the T500 time. The T500 time is reported to the nearest $4 \mathrm{sec}$. The largest diameter of the flow spread of the concrete and the diameter of the spread at right angles to it are then measured and the mean is the slump-flow. Which is the mean diameter of slump flow test expressed to the nearest $10 \mathrm{~mm}$, expressed as $\mathrm{df}$.

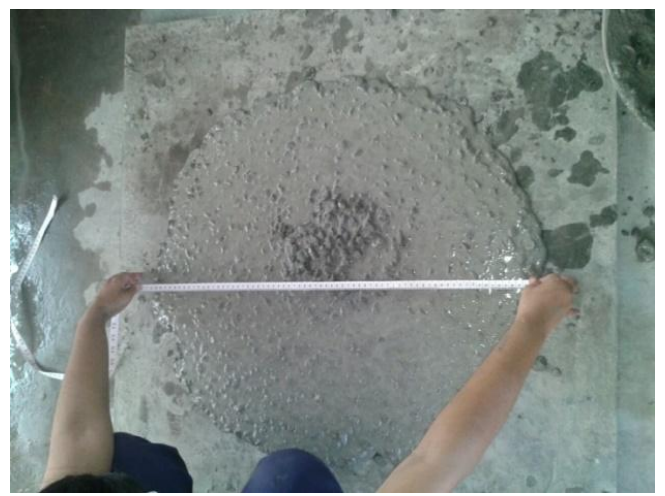

Fig 2.1.1 Check for slump flow

\subsubsection{V-Funnel Test}

The V-funnel test is used to assess the viscosity and filling ability of SCC. A V shaped funnel is filled with fresh concrete and the time taken for the concrete to flow out of the funnel is measured and recorded in second is the V-funnel flow time. It is expressed as tv and reported to the nearest $11 \mathrm{sec}$.

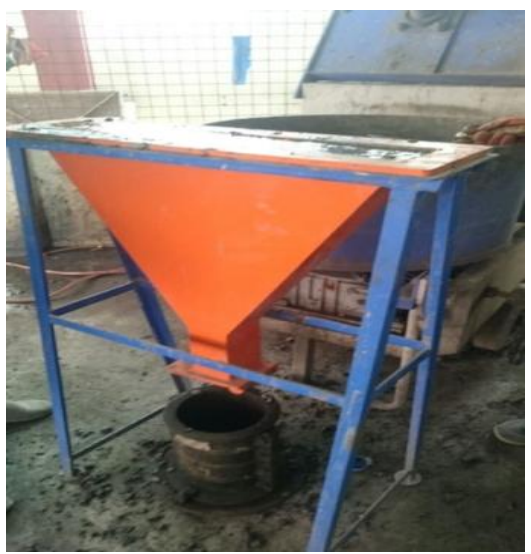

Fig 2.1.2: V-funnel 


\subsubsection{L-Box Test}

The L-box test is used to assess the passing ability of self-compacting concrete to flow through tight openings including spaces between reinforcing bars and other obstructions without segregation or blocking. There are two variations; the two bar test and the three bar test. The three bar test simulates more congested reinforcement.

A measured volume of fresh concrete is allowed to flow horizontally through the gaps between vertical, smooth reinforcing bars and the height of the concrete beyond the reinforcement is measured. Height of the horizontal section of the box measured as $\mathrm{H} 2 \mathrm{~mm}$. The depth of concrete immediately behind the gate measured as $\mathrm{H} 1 \mathrm{~mm}$.

The passing ability $\mathrm{PA}$ is calculated from the equation, $\mathrm{PA}=\mathrm{H} 2 / \mathrm{H} 1$

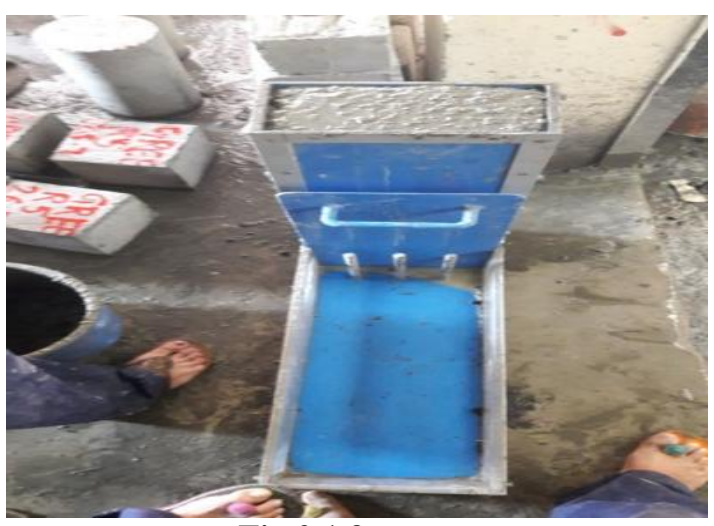

Fig 2.1.3: L-Box

\subsection{Compressive Strength Test}

Three cubes were cast for each mix and its average compressive strength after 28 days was determined as shown in fig 2.2

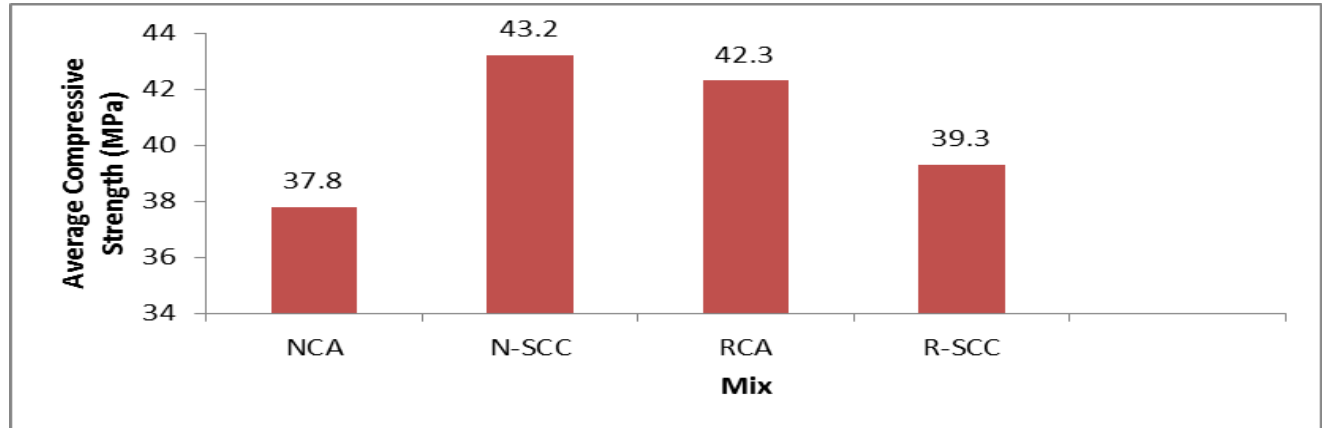

Fig 2.2: comparison of compressive strength

\subsection{Split Tensile Test}

Three cylinders were caste for each mix and the results of split tensile strength of various samples are given in fig 2.3.

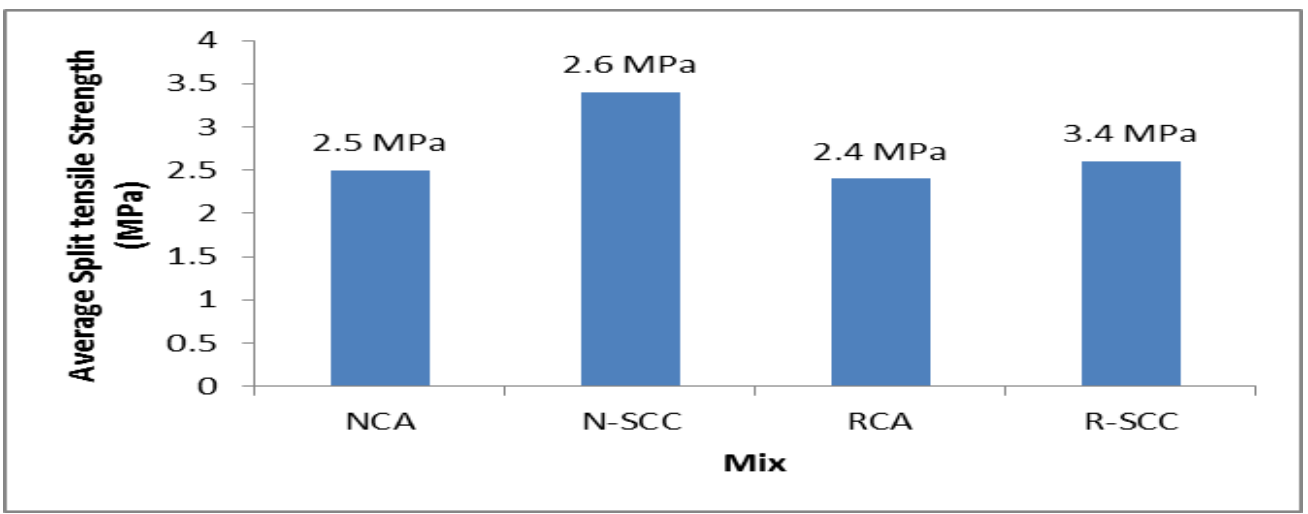

Fig 2.3: Comparison of split tensile strength 


\subsection{Flexural Strength}

Three beams were caste for each mix and the results of flexural strength tests of various samples are shown in fig 2.4.

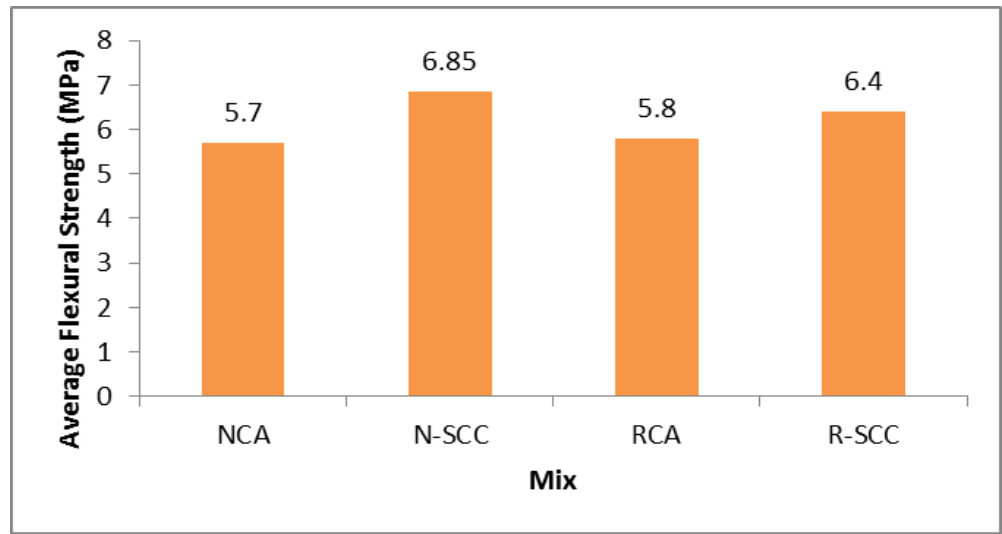

Fig 2.4: Comparison of flexural strength

\subsection{Modulus Of Elasticity}

The modulus of elasticity was determined by subjecting cylinders to uniaxial compression and measuring the deformation by dial gauges which is fixed between gauge length.

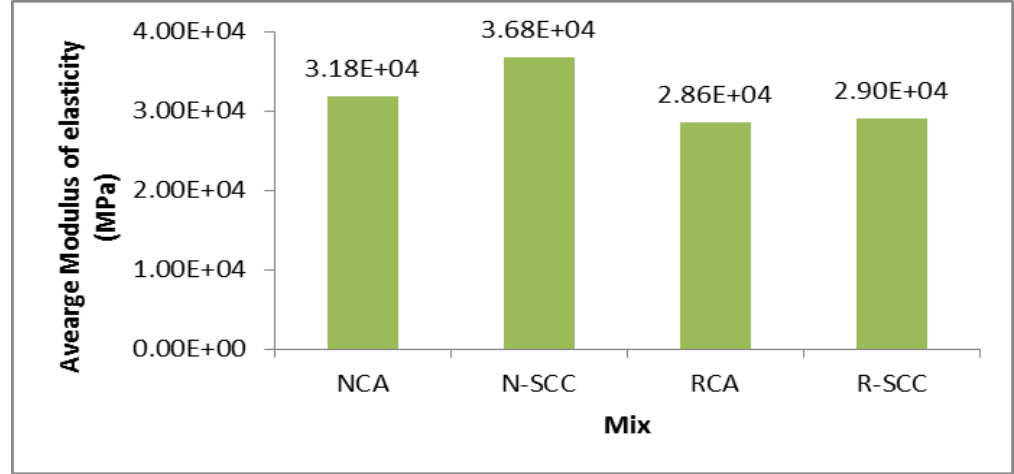

Fig 2.5: Comparison of compressive strength

\subsection{Ultrasonic Pulse Velocity Test}

The technique has been successfully used for the measurement and detection of cracks. The rating has been done as suggested by Central Water and Power Research Station, Khadakwasla (India).

\subsection{Schmidt Hammer Test}

A Schmidt hammer, also known as a Swiss hammer or a rebound hammer, is a device to measure the elastic properties or strength of concrete or rock, mainly surface hardness and penetration resistance.

\subsection{Durability Studies}

Durability of concrete is defined as "Its ability to resist weathering action, chemical attack, abrasion, or any other process of deterioration", and hence to retain its original shape, dimension, quality and serviceability in the working environment during its anticipated service life.

\subsubsection{Deterioration Studies}

\subsubsection{Sulphate Attack}

Resistance to sulphate attack was determined by immersing concrete cubes, after 28-days of water curing in 5\% magnesium sulphate and 5\% sodium sulphate solution by volume of water and determined the reduction in weight and change in compressive strength due to sulphate attack at 30 days interval till 90 days.

\subsubsection{Acid Attack}

In order to evaluate the degree of deterioration of two concrete mixes against accelerate Sulphuric Acid, concrete cubes were immersed in 3\% sulphuric acid solution and the $\mathrm{pH}$ was maintained 4 throughout. At 30 days of interval, difference in weight and change in compressive strength has been observed for 90 days. 
Table 2.8.1: Initial readings for specimens in acid solution

\begin{tabular}{|l|l|l|l|l|l|l|}
\hline \multicolumn{7}{|c|}{ INITIAL } \\
\hline Mix & $\begin{array}{l}\text { Weight } \\
(\mathrm{kg})\end{array}$ & $\begin{array}{l}\text { UPV } \\
(\mathrm{km} / \mathrm{s})\end{array}$ & General condition & $\begin{array}{l}\text { Quality } \\
\text { Classification }\end{array}$ & $\begin{array}{l}\text { Hammer N0. } \\
(\text { No. })\end{array}$ & $\begin{array}{l}\text { Comp. } \\
\text { Strength(kN) }\end{array}$ \\
\hline NCA & 8.092 & 4.23 & Excellent & Very Good & 25 & 37.8 \\
\hline RCA & 7.68 & 4.06 & Excellent & Very Good & 26 & 42.3 \\
\hline N-SCC & 8.005 & 4.5 & Excellent & Very Good & 28 & 43.2 \\
\hline R-SCC & 7.795 & 4.32 & Excellent & Very Good & 26 & 39.3 \\
\hline
\end{tabular}

Table 2.8.2: Initial readings for specimens in magnesium sulphate solution

\begin{tabular}{|l|l|l|l|l|l|l|}
\hline \multicolumn{7}{|c|}{ INITIAL } \\
\hline Mix & $\begin{array}{l}\text { Weight } \\
(\mathrm{kg})\end{array}$ & $\begin{array}{l}\text { UPV } \\
(\mathrm{km} / \mathrm{s})\end{array}$ & General condition & $\begin{array}{l}\text { Quality } \\
\text { Classification }\end{array}$ & $\begin{array}{l}\text { Hammer N0. } \\
(\text { No. })\end{array}$ & $\begin{array}{l}\text { Comp. } \\
\text { Strength(kN) }\end{array}$ \\
\hline NCA & 8.053 & 4.27 & Excellent & Very Good & 24 & 37.8 \\
\hline RCA & 7.627 & 4.11 & Excellent & Very Good & 26 & 42.3 \\
\hline N-SCC & 8.042 & 4.52 & Excellent & Very Good & 27 & 43.2 \\
\hline R-SCC & 7.847 & 4.24 & Excellent & Very Good & 26 & 39.3 \\
\hline
\end{tabular}

Table 3.8.3: Initial readings for specimens in sodium sulphate solution

\begin{tabular}{|l|l|l|l|l|l|l|}
\hline \multicolumn{7}{|c|}{ INITIL } \\
\hline Mix & $\begin{array}{l}\text { Weight } \\
(\mathrm{kg})\end{array}$ & $\begin{array}{l}\text { UPV } \\
(\mathrm{km} / \mathrm{S})\end{array}$ & General condition & $\begin{array}{l}\text { Quality } \\
\text { Classification }\end{array}$ & $\begin{array}{l}\text { Hammer N0. } \\
(\text { No. })\end{array}$ & Comp. Strength(kN) \\
\hline NCA & 8.045 & 4.3 & Excellent & Very Good & 25 & 37.8 \\
\hline RCA & 7.717 & 4.11 & Excellent & Very Good & 25 & 42.3 \\
\hline N-SCC & 7.991 & 4.58 & Excellent & Very Good & 28 & 43.2 \\
\hline R-SCC & 7.780 & 4.26 & Excellent & Very Good & 26 & 39.3 \\
\hline
\end{tabular}

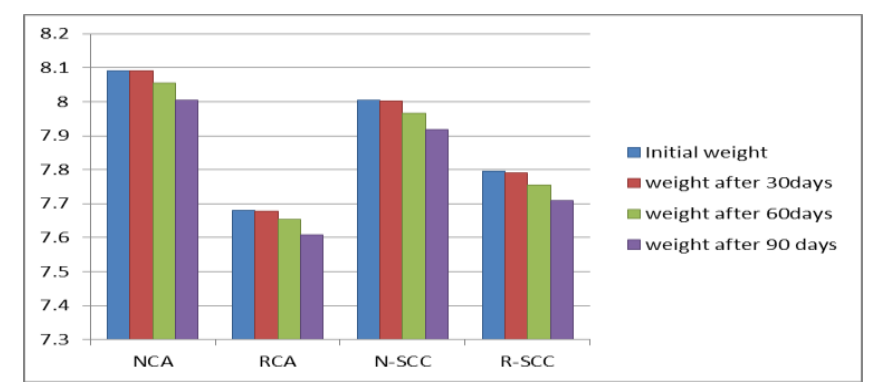

Fig 2.8.1: Weight loss of specimens in acid solution

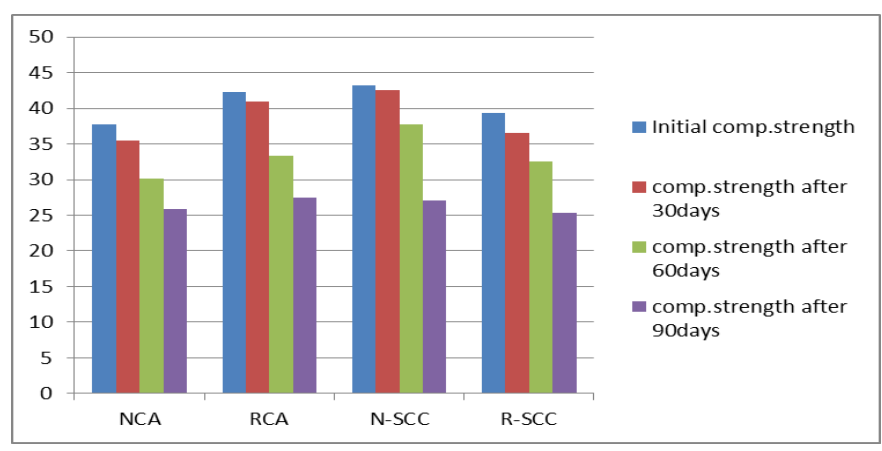

Fig 2.8.2: Strength loss in specimens in acid solution

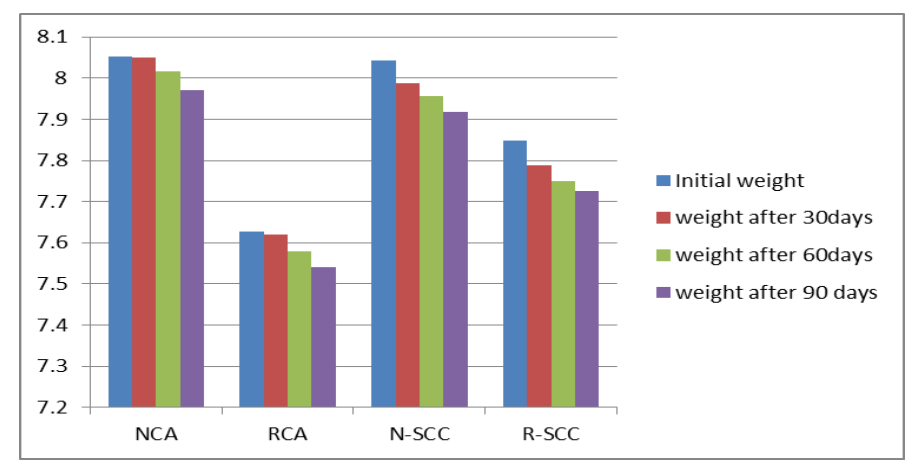

Fig 2.8.3: Weight loss of specimens in magnesium sulphate solution 


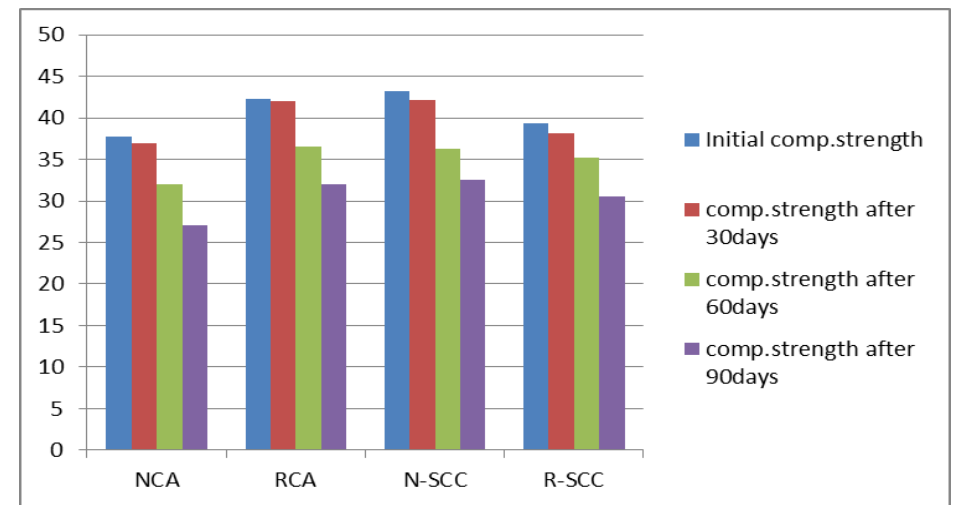

Fig2.8.4: Strength loss of specimens in magnesium sulphate solution

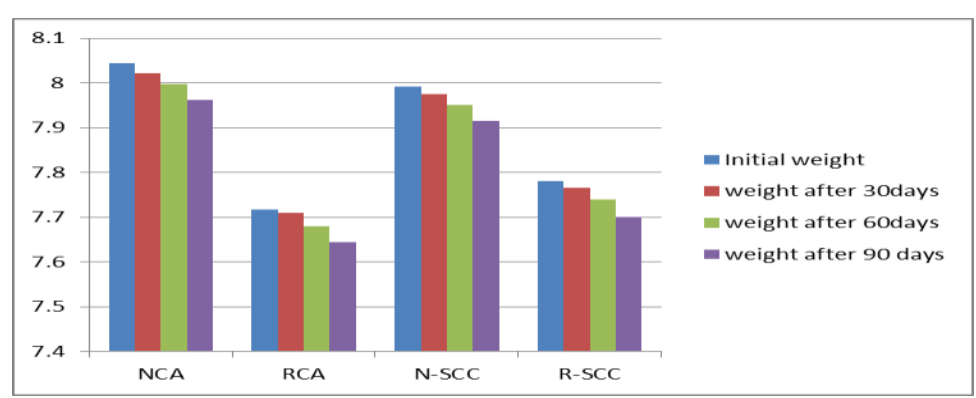

Fig 2.8.5 Weight loss of specimens in sodium sulphate solution

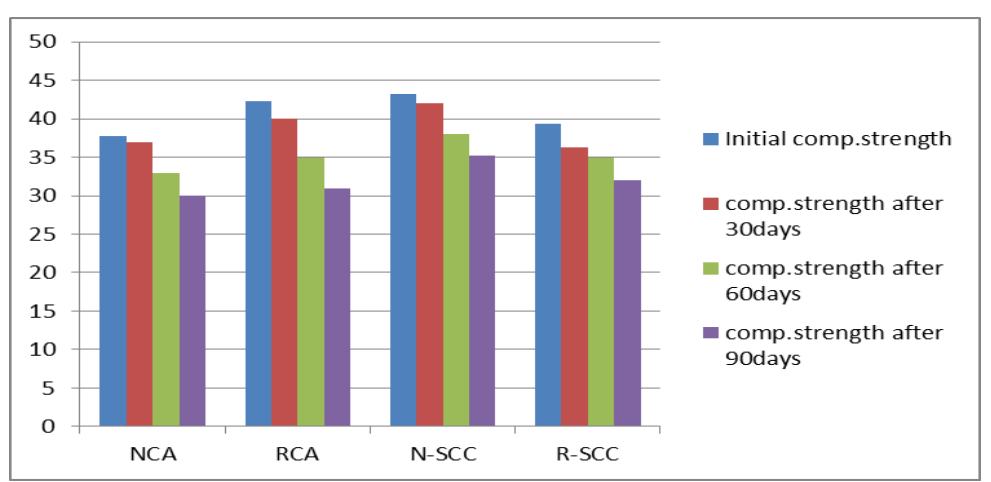

Fig 2.8.6: Strength loss of specimens in sodium sulphate solution

\section{Conclusions}

- The compressive strength of RCA and NCA is about $90 \%$ of SCC made with R-SCC and N-SCC. Since the loss of strength is very less, the recycled coarse aggregates can be effectively used as a replacement to normal coarse aggregates.

- Flexural strength RCA and NCA of was found to be $93 \%$ of that with R-SCC and N-SCC mix. Since the maximum reduction is just around $6 \%$, it is encouraging to promote the use of RCA in structural concrete.

- Split tensile strength for RCA and NCA was found to be around 70-80\% of that with R-SCC and N-SCC mix.

- Elastic Modulus of R-SCC is found to be lower than N-SCC.

- The Durability of concrete with recycled coarse aggregate under sulphate and acid action is higher superior to the conventional concrete.

- It was also found that compressive strength of specimens with NCA and RCA is comparable.

- The durability studies shows weigth loss of about 2-3\% and reduction in compressive strength of $5-10 \%$ at an interval of 30days upto 90days.

\section{Reference}

[1] The European Guidelines for Self-Compacting Concrete Specification, Production and Use ,May 2005

[2] Okamura, H.; and Ouchi, M., "Self-Compacting Concrete," Journal of Advanced Concrete Technology, V. 1, No. 1, Apr. 2003, pp. 5-15.

[3] P.Kumar Mehta, Concrete Microstructure, Properties and Materials, Tata Mc. Graw Hill Private Limited

[4] Shetty M. S., Concrete Technology Theory and Practice, S. Chand \& Company Ltd., New Delhi, 2002 
[5] S.W. Tang, Y. Yao, C. Andrade, Z.J. Li , "Recent durability studies on concrete structure”, March 2015.

[6] Kosmas K. Sideris, Nikolaos S. Anagnostopoulos, "Durability of normal strength self-compacting concretes and their impact on service life of reinforced concrete structures", January 2013,pp. 491-497.

[7] M. Benaicha , O. Jalbaud, X. Roguiez, A. Hafidi Alaoui , Y. Burtschell , “ Prediction of Self-Compacting Concrete homogeneity by ultrasonic velocity", August 2015, pp. 1181-1191.

[8] Helena Figueiras, Sandra Nunes, Joana Sousa Coutinho, Carmen Andrade, “ Linking fresh and durability properties of paste to SCC mortar", September 2013, pp. 209-226.

[9] Antonios Kanellopoulos, Michael F. Petrou, Ioannis Ioannou, "Durability performance of self-compacting concrete", September 2012,pp. 320-325.

[10] Jun Liu, Kaifeng Tang, Qiwen Qiu , Dong Pan, Zongru Lei and Feng Xing, “ Experimental Investigation on Pore Structure Characterization of Concrete Exposed to Water and Chlorides",V01.7,September 2014, pp. 6646-6659.

[11] Martin Kaasgaard, Claus Pade and Ulf Jönsson, "Comparison of durability parameters of self-compacting concrete and conventional slump concrete designed for marine environment", pp. 13-24.

[12] K C Panda, P K Bal,"Properties of self-compacting concrete using recycled coarse aggregate”, 2013 , pp. 159 - 164.

[13] Dr. Elson John, Deepthy Varkey, Sija K Sam, "Self Compacting Concrete with Recycled Coarse Aggregates", IJERT September 2014, Vol 3, Issue 9, pp. 105-107

[14] M Vijaya Sekhar Reddy, Ramana Reddy, K Madan Mohan Reddy and C M Ravi Kumar "Durability Aspects Of Standard Concrete", IJSCER, February 2013 Vol. 2, No. 1, pp.40-46.

[15] R. V. Silva, J. de Brito, R. K. Dhir, "Properties and composition of recycled aggregates from construction and demolition waste suitable for concrete production", Construction and Building Materials 65, 2014, pp 201-217

[16] V. S. RamachandranandJames J. Beaudoin "Handbook Of Analytical Techniques In Concrete Science And Technology"Institute for Research in Construction, National Research Council Canada. 